\title{
A Development of Simulator Considering Behavioral Psychology of Japanese to Improve Evacuation Ratio in Flood
}

\author{
Tatsuki Fukuda \\ Dept. of Creative Engineering \\ National Institute of Technology, Kitakyushu College \\ Fukuoka, Japan
}

\begin{abstract}
In Japan, the natural disasters causes a lot of damages of residents. For example, the flood caused by heavy rain and house collapse due to earthquake. As you know, no one can evacuate from earthquake because it is not knowable that when the earthquake will occur. The residents, however, often have chances to evacuate from flood caused by heavy rain because there is a little time left before the flood occurs. In order to improve the evacuation ratio, the system to share the evacuation status of neighbors has been proposed. Although a survey showed that the system is so effective to improve the evacuation ratio, the number of neighbors to share the evacuation status has not been clear. The aim of this study is a development of the simulation of the residents in order to find the optimal number of the neighbors to share the evacuation status. In this paper, the simulator based on the behavioral psychology for the evacuation ratio in flood is considered. The main target in the simulation is the action of human, so the game theory is appliable. The residents, which is players in the game theory or agents in the simulator, will make decisions based on the statuses of their neighbors. In the experiments, the actual evacuation ratio can be obtained by a simulation with a premise that the residents can never know the evacuation status of their neighbors. For the future work, the optimal number of neighbors to share evacuation status should be simulated in view of the improvement of evacuation ratio in flood.
\end{abstract}

Keywords-Simulator; game theory; flood

\section{INTRODUCTION}

These days, we have caught a lot of rains especially in summer. It is said the climate in Japan has changed to a subtropical climate. Because of that, there are a lot of flood due to heavy rain in Japan. Of course there are some natural disasters in Japan such as earthquake, typhoon, and volcanic eruption. You cannot forecast the occurrence of an earthquake nor volcanic eruption, but you can roughly forecast the occurrence of flood because it is due to at least several tens of minutes' heavy rain. Even though you may not forecast exactly whether or not that a flood will occur, but you have enough time to evacuate before the flood occurs.

A survey showed that the evacuation ratio was about $4.6 \%$ in flood occurred in 2018[1]. As you can guess, most of the residents were able to evacuate but they didn't. That's because they thought that they couldn't suffer from the flood. The more residents evacuate, the less the damage get to be. Therefore, the system to improve the evacuation ratio is so important and the urgent task.
The floods are so horrifying to humankind and a lot of research have been done to escape them. For example, the develop of the hazard map[2][3], the speed of persons evacuating in water of flood[4], the simulation of the urban flood[5], and so on.

These researches are useful after the evacuation ratio gets high enough, but the actual ratio is not. A lot of persons keep staying home while the crisis is approaching, and they are probably just looking at the screen of televisions or smartphones or the outside window because they are afraid that their home would be flooded actually. Fortunately, the modern persons can use not only global broadcast as an information source, but also a lot of social media such as Twitter and Facebook. Therefore, the social media is one of the "keys" to make persons evacuate.

The persons can "talk" with others in social media and it's different from the televisions or radio[6][7][8]. Therefore, the persons can not only receive the information but also ask the situation in which theirselves are to someone in social media. In [9], the social media can reduce the evacuation ratio because the inaccurate or misleading information in social media. However, that means the accurate information or reliable information is important to improve the evacuation ratio.

By the way, Japanese people strongly tend to think that an action which is not similar to the others is so embarrassing[10]. In other words, a person do something because the other persons do so. This is also known as the bandwagon effect[11]. Therefore, the persons will evacuate if the other persons, especially the neighbors evacuate. On the other hand, in modern Japanese society they have little communication with neighbor residents [12]. Many persons, especially young persons doesn't know even the face of neighbors. That's why the residents cannot get the information whether or not the neighbors have already evacuated in flood, and they cannot evacuate because they think "the neighbors should still be at home."

A novel system to solve the problem by sharing the evacuation status of neighbors without communication of face to face have already proposed[13]. The system is so accurate because the system gives the information whether or not the persons have been evacuated. Of course, one can push the button even though they keep staying home, or one can forget to push the button even though they begin to evacuate but the system gives the information as the "evacuation ratio," so the 
acts of irregular become inconspicuous regardless of malicious intents. That means the system have a possibility to improve the evacuation ratio.

Persons, however, may not be able to decide to evacuate if they're sharing only one neighbor's status each other, and they also may not decide to evacuate if they're sharing the evacuation status of all residents in their town. Therefore, the optimal number of neighbors the residents should share is needed in order to use the system efficiently.

In this paper, the system to share the evacuation status is shown in Section II and explain the game theory in order to simulate the residents' action of evacuation in Section III. After that, the new simulation method to obtain the optimal number of neighbors is shown in Section IV. With the simulation, the optimal number of neighbors to share the evacuation status will be obtained.

\section{EVACUATION-STATUS-Sharing System}

Prior to the study, a questionnaire survey was conducted to determine what to use when deciding whether to evacuate. The subjects of the questionnaire are 1,000 men and women in their teens and 80s. The questionnaire of the questionnaire is as follows.

- When you decide whether or not to evacuate during a heavy rain, which is more influential, the evacuation status of neighbors or official evacuation advisory?

- Do you care whether people around your home have evacuated when you decide to evacuate during a heavy rain?

- When you decide whether or not to evacuate during a heavy rain, which of the following situation will make you more likely to evacuate?

(a) The official evacuation advisory is not issued but the almost of all neighbors have evacuated.

(b) The official evacuation advisory have been issued but the almost of all neighbors stay home.

- Which of the following situations would you consider starting evacuation in a heavy rain? (Note that the "alert level" in the following choices is defined in the 5-point scale for Severe Weather Preparation Information.)

(a) I don't care about the neighbors.

(b) Almost all of the neighbors have evacuated.

(c) $80 \%$ of the neighbors have evacuated.

(d) $50 \%$ of the neighbors have evacuated.

(e) $30 \%$ of the neighbors have evacuated.

(f) $10 \%$ of the neighbors have evacuated.

(g) The official issued alert level 4 near home (Evacuation advisory or instructions).

(h) The official issued alert level 3 near home (Evacuation preparations).

(i) The official issued alert level 4 in the neighboring town (Evacuation advisory or instructions).

(j) The official issued alert level 3 in the neighboring town (Evacuation preparations).

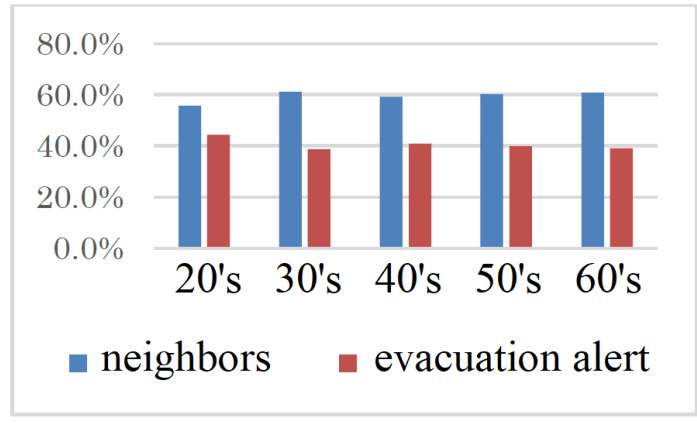

Fig. 1. Questionnaire 1: When you decide whether or not to evacuate during a heavy rain, which is more influential, the evacuation status of neighbors or official evacuation advisory?

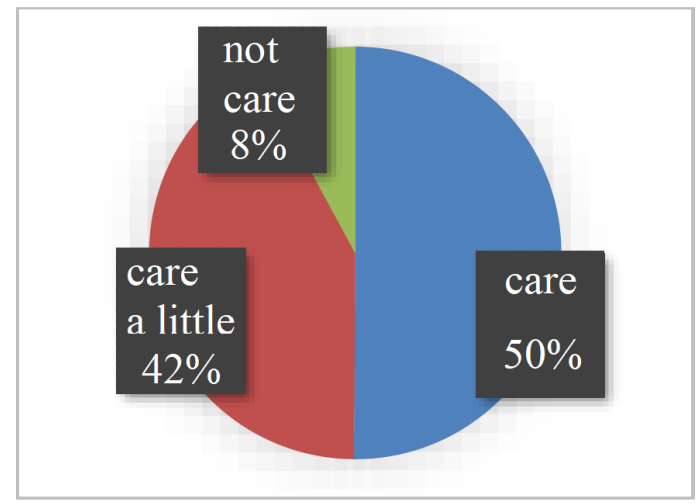

Fig. 2. Questionnaire 2: Do you care whether people around your home have evacuated when you decide to evacuate during a heavy rain?

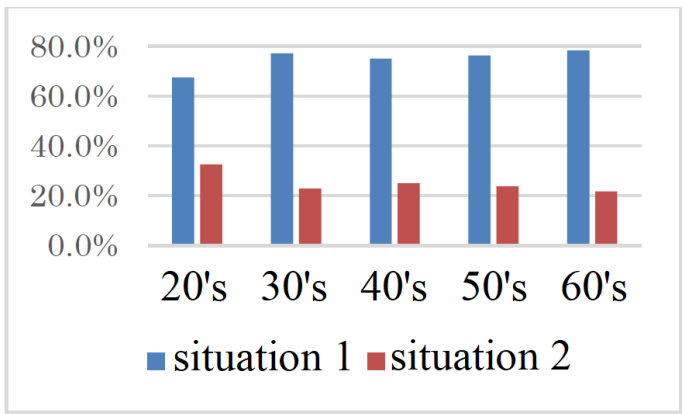

Fig. 3. Questionnaire 3: When you decide whether or not to evacuate during a heavy rain, which of the following situation will make you more likely to evacuate? Fig. 4.

The results of these questionnaires are shown in Fig. 1 to

As you see in from Fig. 1 to Fig. 3, regardless of age, about $60 \%$ persons think the neighbors' evacuation status are more influential than the other (Fig. 1). So, the other persons don't care about neighbors? That's not true. They do care about neighbors. The Fig. 2 shows that more than $90 \%$ persons care about the status of neighbors. Not only they care of the neighbors, they think the neighbors' status is more important factor to decide whether or not evacuate than the official evacuation advisory (Fig. 3). Then how many neighbors are needed to make residents evacuate? You can see that about 


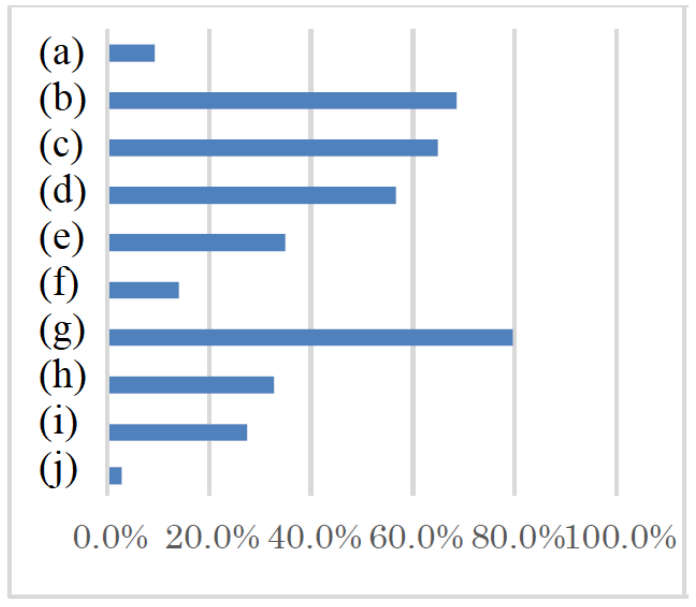

Fig. 4. Questionnaire 4: Which of the following situations would you consider starting evacuation in a heavy rain?

$50 \%$ residents will evacuate if a half of neighbors evacuated (Fig. 4). Therefore the system to share the neighbors' evacuation status is so effective to improve the evacuation ratio. You can also notice in Fig. 4 that about $80 \%$ persons think they will evacuate if the evacuation alert level 4 is issued near their home. They, however, may not be able to evacuate because the depth of the water in front of their house is too deep to evacuate safely. If the depth of water becomes as high as knee level, it is so difficult to walk around safely. It follows that all of $80 \%$ persons who decide to evacuate can not always evacuate even if the evacuation alert level 4 is issued.

The fear of sharing neighbors' status is that all of the residents think "I don't need to evacuate because the sharing system shows that nobody have evacuated," because the sharing system also share the status of "nobody have evacuated." You, however, don't think about the fear because Fig. 4 shows that about $10 \%$ persons don't care whether or not neighbors evacuated, so they will evacuate according to the evacuation advisory. Now, consider the number of neighbors to share the evacuation status with the game theory.

\section{GAME THEORY}

With a sharing system of evacuation status, the residents think whether or not evacuating is better than staying home. In one survey, the residents thought "I will be ashamed if I become the only one to evacuate," although they should have known it's safer to evacuate than keep staying home. Probably, that is the Japanese. The residents thought what is the best action for themselves. Therefore, their thinking can be simulate with game theory. Note that the best action for a resident is not always one to save a life. It is often the action not to be ashamed. Most of Japanese people think that they are "ashamed" if their action is not similar to the others.

As you know, the game theory is well-known method to simulate the social situations among competing players [14]. There are two kinds in the game theory, noncooperative game theory and the cooperative game theory. In this evacuation problem, which one is the suitable? The answer in Japanese society in modern is "noncooperative," because there are little community between neighbors. It is said that the residents don't know the neighbors' face each other.

\section{Simulation Method}

In this paper, we propose the multi-agent simulator of the residents action whether or not evacuate and the simulation is based on the following factors.

- The "agents" are residents in a town.

- The agents in $10 \%$ evacuate according to the alert level; They evacuate in the probability of $18.6 \%$ at the alert level 3 or $79.6 \%$ at the level 4 .

- The agents in $90 \%$ decide to evacuate according to the neighbors' evacuation status and alert level of the 5-point scale for Severe Weather Preparation Information. The probability to evacuate is based on the results of our survey in Section II.

- The agents know whether or not the neighbors have evacuated. The number of neighbors a resident can know is changable.

- $\quad$ The agents are defined per household.

- The residents cannot evacuate if the depth of water in front of their house is more than a half of meter.

- The time series should be based on actual events after heavy rain. It means that the damage spreads depending on the geography.

The prototype of the simulator including the above factors except for the last one has been developed. Now, the algorithm of the simulation is shown below.

\section{Algorithm}

1) Generate the agents.

2) Place the agents in random location.

3) decide the number of neighbors to share the evacuation status.

4) Advance the time.

5) The official issues the evacuation alert properly.

6) The agents decide whether or not evacuate according to the probability calculated by the result of survey.

7) The damage spreads from the point of the river overflowed according to the time.

8) Finish the simulation if the flood calms down or the all of the residents left in their house get not able to evacuate, or return to 3 ).

When the simulator stopped, the evacuation ratio is obtained. Our goal is improvement of the evacuation ratio by adjusting the number of neighbors to share the status. The statuses of agents in the simulation are displayed like Fig. 5, where the agents and area situation are colorized according to the status. The colorization rule is shown in Table I and Table II. 


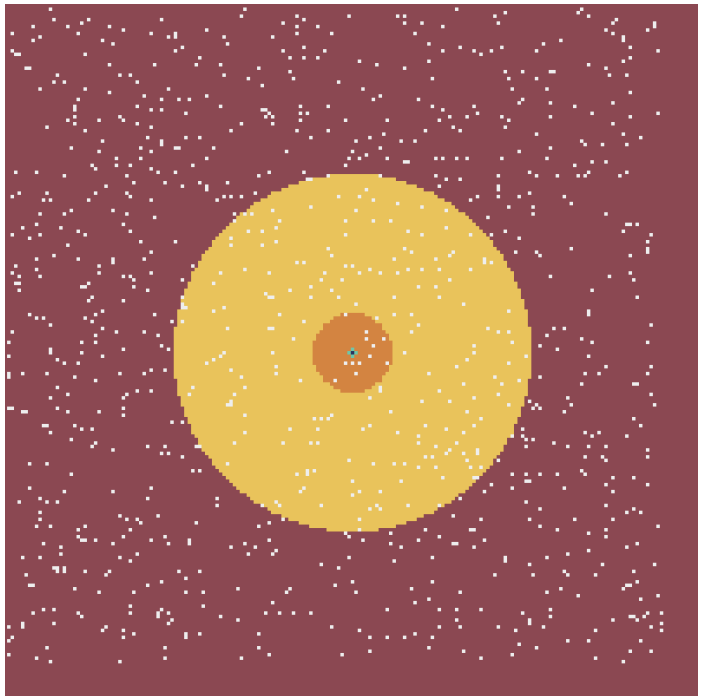

(a)

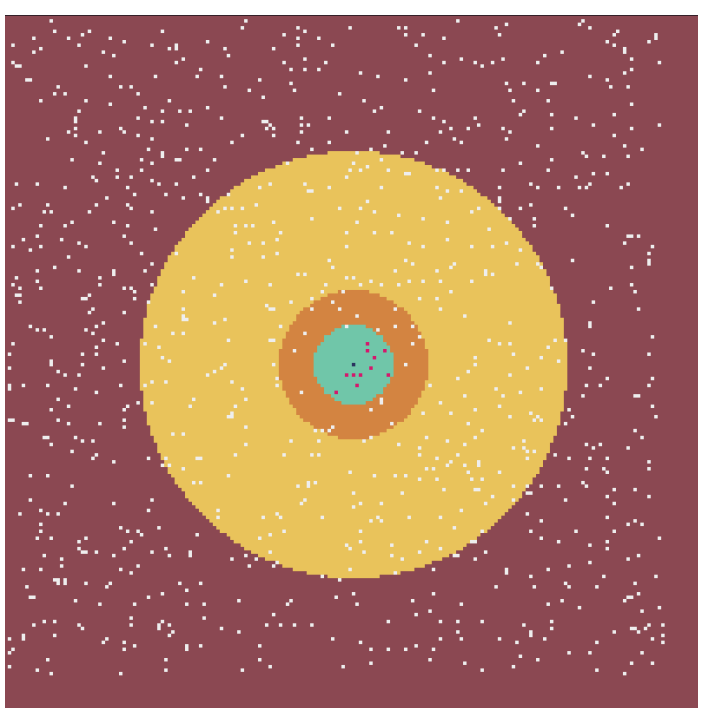

(b)

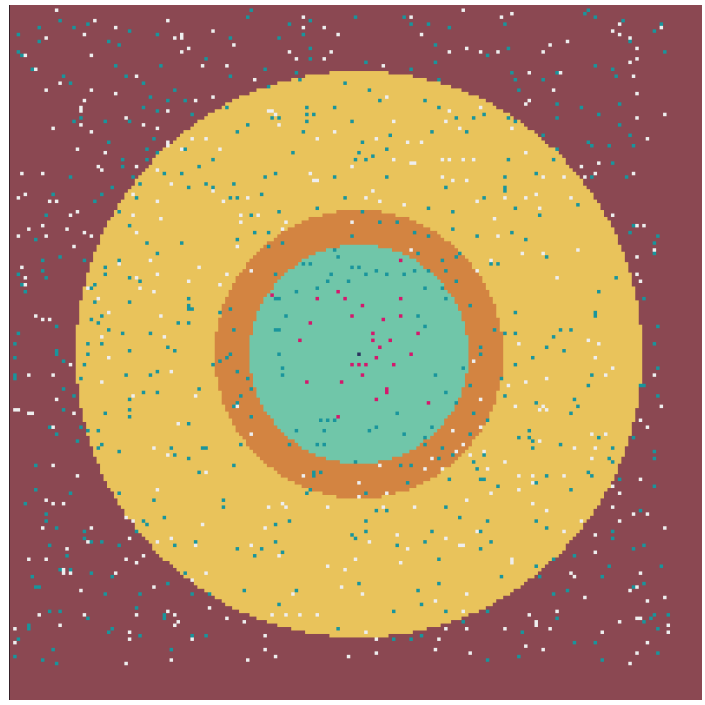

(c)

Fig. 5. The simulator displays the statuses of agents, which are distinguished by the color. The displayed statuses change in order from (a) to (c).
TABLE I. COLORIZATION FOR THE AREA

\begin{tabular}{|c|l|}
\hline Color & Status \\
\hline Brown & The area of not flooded. \\
\hline Light blue & The area of flooded. \\
\hline Dark blue & The point of the river overflowed. \\
\hline Yellow & The area that alert level 3 is issued. \\
\hline Orange & The area that alert level 4 is issued. \\
\hline
\end{tabular}

TABLE II. COLORIZATION FOR THE AGENT'S STATUS

\begin{tabular}{|c|l|}
\hline Color & Status \\
\hline Gray & An agent who has evacuated according only to the alert only. \\
\hline Green & An agent who has evacuated \\
\hline White & An agent who keep staying home. \\
\hline Red & An agent who cannot evacuate and forced to keep staying home. \\
\hline
\end{tabular}

\section{EXPERIMENT}

In order to verify the simulator, some experiments have been conducted. In the experiments, the following parameter were changeable.

- The speed at which the flood spreads.

- The alert area.

- The number of neighbors to share the evacuation statuses.

The assumed speed at which the flood spreads is referring to the data of the actual flood in 2018 at the Mabi-cho in Okayama prefecture in Japan. Note that this simulator is just a prototype and the geographic factor is not concerned, so the following parameters may be different in detail from the actual flood.

- The flood spreads concentrically from the central point of the screen.

- The speed at which the flood spreads is assumed to be $0.167 \mathrm{~m} / \mathrm{s}$.

- The alert-3 area is the $500 \mathrm{~m}$ outside the flood area.

- The alert-4 area is the $100 \mathrm{~m}$ outside the flood area.

In the experiments, the number of the neighbors to share the statuses are different (Table III).

TABLE III. EXPERIMENTAL CONDITIONS

\begin{tabular}{|c|c|}
\hline The experiment number & The number of neighbors to share the statuses \\
\hline 1 & Decided according to the survey. \\
\hline 2 & 0 \\
\hline 3 & 10 \\
\hline 4 & 20 \\
\hline 5 & 50 \\
\hline 6 & 100 \\
\hline 7 & 200 \\
\hline
\end{tabular}

In experiment 1 , the number of neighbors to share the statuses is decided according to the another survey "how many neighbors do you think to want to share the evacuation statuses if you can," and the result is shown in Fig. 6. That means that the $46 \%$ of the agents can know 10 neighbors' statuses, $29 \%$ can know $25 \%$ neighbors', and so on. 


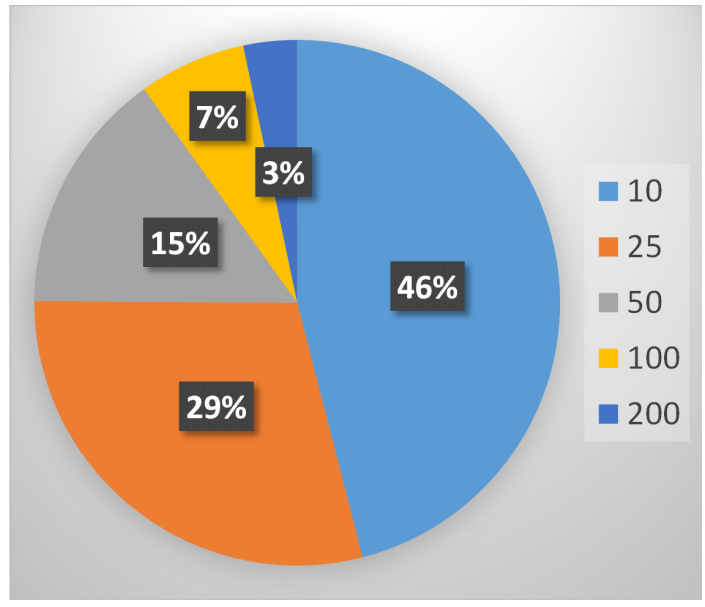

Fig. 6. Questionnaire 5: The number of neighbors to share the evacuation statuses.

we conducted 1000 times simulation to get the average evacuation ratio in each experiments, and the results are shown in Table IV.

TABLE IV. EXPERIMENTAL RESULTS

\begin{tabular}{|c|c|}
\hline The experiment number & The evacuation ratio \\
\hline 1 & $87.1 \%$ \\
\hline 2 & $6.3 \%$ \\
\hline 3 & $84.5 \%$ \\
\hline 4 & $88.6 \%$ \\
\hline 5 & $87.4 \%$ \\
\hline 6 & $88.5 \%$ \\
\hline 7 & $89.4 \%$ \\
\hline
\end{tabular}

\section{DISCUSSION}

In the experiment 2 , the evacuation ratio is $6.3 \%$ and it's almost the same as the actual evacuation raio[15]. It means that the residents in the situation of actual flood couldn't know the statuses of neighbors and they couldn't make their mind to evacuate. The evacuation ratio are different due to the number of neighbors to share the evacuation statuses. Basically, the more the number of neighbors becomes, the more agents come to evacuate. That's because they think "Oh, so many people have already evacuated," if they can get a lot of statuses of neighbors. The evacuation ratio, however, doesn't continue to increase much even though the number of neighbors to share the statuses increases. That's because it takes a while that the evacuation ration in the neighbors increases if the number of neighbors to share the statuses comes to big. Therefore, the optimal number of the neighbors to share the statuses is needed. By the way, this result is obtained with at lest two limitations. First is that the flood spreads concentrically at the same speed. Second, the persons make decisions just like the results of survey, so these results are especially suitable for Japanese.

\section{CONCLUSION}

In this paper, the simulator which consider the behavioral psychology of Japanese was proposed. Japanese people think they're so ashamed if their action is not the same as the others.
Therefore, a resident comes to evacuate as early as possible if the neighbors have already evacuated. On the other hand, the community between residents becomes thinner than before, so the residents cannot get the information whether or not the neighbors have already evacuated. That result in the low ratio of evacuation. With our system to share the evacuation statuses of neighbors, the residents can get the information whether or not the neighbors have evacuated easily, but the number of neighbors to share the information is a problem. It's not good that the number of that is too small because the residents think "just a few persons have evacuated," while it's also not good that the number of that is too big because the evacuation ratio in the neighbors increases slowly.

\section{FUTURE WORK}

The result of simulation is reliable because the simulator based on the result of survey. This simulator, however, is a prototype so that the geographic factor is not considered, the time needed to evacuate for residents, the case that the road to use for evacuation is not available, and so on. These factors should be considered in the future work and obtaining the optimal number of neighbors to share the evacuation status is a final goal of this study.

\section{REFERENCES}

[1] Ministry of Land, Infrastructure, Transport and Tourism, "Overview of damages due to heavy rain in July 2018," 2018.

[2] Knapp, Landon and Levine, Norman S and Watson, Sarah, "The Flood Disruption Scale: Communicating High Resolution Flood Hazard Modeling and Mapping in the Charleston South Carolina Region," AGUFM, pp.PA33C-1109, 2019.

[3] Tehrany, Mahyat Shafapour and Jones, Simon and Shabani, Farzin, "Identifying the essential flood conditioning factors for flood prone area mapping using machine learning techniques," Catena, Vol.175, pp.174192, 2019.

[4] Bernardini, G., Quagliarini, E., D’Orazio, M., and Brocchini, M., "Towards the simulation of flood evacuation in urban scenarios: Experiments to estimate human motion speed in floodwaters," Safety Science, Vol.123, Article 104563, 2020.

[5] Bertsch, Robert and Glenis, Vassilis and Kilsby, Chris, "Urban flood simulation using synthetic storm drain networks," Water, Vol.9, No.12, p.925, 2017.

[6] Asur, S., and Huberman, B. A., "Predicting the future with social media," in Proceedings of the international conference on web intelligenceand intelligent agent technology, pp.492-499, 2010.

[7] Homero Gil de Zúñiga and Trevor Diehl, "Citizenship, Social Media, and Big Data: Current and Future Research in the Social Sciences," Social Science Computer Review, Vol.35, No.1, pp.3-9, 2017.

[8] Kwak, Haewoon and Lee, Changhyun and Park, Hosung and Moon, Sue, "What is Twitter, a Social Network or a News Media?," in Proceedings of the 19th International Conference on World Wide Web, pp.591-600, 2010.

[9] Du, E., Cai, X., Sun, Z., and Minsker, B., "Exploring the role of social media and individual behaviors in flood evacuation processes: An agentbased modeling approach," Water Resources Research, Vol.53, No.11, pp.9164-9180, 2017.

[10] Takanobu YAMADA, "Japanese 'Shame Culture'," Mejiro University College Departmental Bulletin Paper, Vol.44, pp.A1-A13, 2008.

[11] Leibenstein H., "Bandwagon, Snob, and Veblen Effects in the Theory of Consumers' Demand," Quarterly Journal of Economics (64:2), pp. 183-207, 1950.

[12] Masahiro NAKASHIMA, "Thoughts on Reviving a Local Community : Considerations Based on Social Capital Studies in Japan," Hiroshima Journal of International Studies, Vol. 15, pp.89-101, 2009. 
[13] Tatsuki FUKUDA, "Hinan surune! botan wo Mochiita Hinansokushin sisutemu no Kaihatsu (A Development of Evacuation Promotion System with a Button of 'Already Evacuated')," Research Report of National Institute of Technology, Kitakyushu College, Vol.53 January, 2020.
[14] Myerson, Roger B., Game theory, Harvard university press, 2013.

[15] Ministry of Land, Infrastructure, Transport and Tourism, "Chikugoto ni Bousai ni Torikumu hitsuyousei ni tsuite (About the necessity of working on disaster prevention in each district)," 2019. 